Fecha de entrega: 20 de noviembre de 2009

Fecha de aprobación: 22 de febrero de 2010

\title{
EL GAUCHO COMO SUJETO SOCIAL APORTES DESDE LA PINTURA Y LA LITERATURA
}

\section{THE GAUCHO AS SOCIAL SUBJECT. PAINTING Y LITERATURE CONTRIBUTIONS}

\author{
Sebastián Senlle Seif*
}

\section{Resumen}

El artículo es el análisis de algunos estudios realizados sobre el gaucho en los que se emiten juicios de valor acerca de la pertinencia o impertinencia de utilizar fuentes literarias o pictóricas para ayudarnos a comprender la historia argentina. Más aún, para indagar si pueden resultar útiles al estudiar los pasados subalternos que han quedado desplazados del relato nacional. Además de la discusión de posiciones teóricas, se presentan dos ejemplos a través de los cuales se intenta justificar la utilidad de usar dichas fuentes para enriquecer los estudios históricos. Finalmente, se inicia un debate historiográfico acerca de la posibilidad o imposibilidad de hallar espacios de enunciación o huellas de las voces silenciadas de los sectores subalternos.

\section{Palabras clave}

Gaucho, sujetos subalternos, pasados subalternos, pintura - literatura.

\section{Abstract}

This study aims to revise some studies about the gaucho, where value judgments about pertinence or impertinence of using literary or pictorial fountains to help us to comprehend argentine history are emitted. Moreover, to investigate if they could be useful to study the subaltern pasts that have been displaced from the national tale. Besides de theoretical discussion, two examples are presented through which we aim to justify the utility of

Facultad de Ciencias Sociales, Universidad de Buenos Aires. 
using that fountains to enrich historical studies. Finally, a historiographic debate is initiated about the possibility or not of finding enunciating spaces or traces of the subaltern sector's silenced voices.

\section{Key words}

Gaucho, subaltern subjects, subaltern pasts, painting, literature.

\section{Introducción}

En este trabajo intento acercarme a un fenómeno de la historia social y cultural argentina que implicó un proceso gradual de cambio social; pero además, es preciso considerar que se trató simultáneamente de un proceso que llevó consigo una generación de desigualdades de diverso tipo. Por el carácter que intento imprimirle a esta monografía, me detendré especialmente en aquellas de tipo cultural. Esta empresa pretende además vincular lo más abiertamente posible una serie de contribuciones de diversas disciplinas de estudio para enriquecer el trabajo. Así, junto con observaciones históricas y discusiones historiográficas, buscaremos establecer vínculos con la literatura y el arte pictórico, desde una perspectiva socio-antropológica ${ }^{1}$.

La formación/construcción de la nacionalidad argentina fue y continúa siendo estudiada por diversas disciplinas. En este caso, se busca

1 Considero que desde el punto de vista teórico y epistemológico ya no es posible delimitar claramente objetos de estudio rígidos y específicos de la sociología del arte o de la cultura, la antropología social o cultural, así como la historia o la semiótica del arte. Así, la propuesta es realizar una mirada socio-antropológica en la cual no se piense en "sociología" o "antropología" aplicadas a las formas estéticas, las obras de arte o el público receptor del arte (aunque estas cosas deban ser atendidas para complejizar el análisis) sino ver el modo en que una perspectiva socio-antropológica puede aportar a la lectura de la praxis estético-cultural, para dar cuenta del modo en que el arte permite pensar la sociedad, la cultura y la política. examinar el fenómeno desde el plano cultural y más precisamente desde el terreno de lo simbólico que, como a principios del siglo XIX, influye hasta nuestros días en la identidad argentina. El ejemplo más sobresaliente en este sentido, es la Marcha Patriótica (más tarde Himno Nacional Argentino) encargada a Vicente López y Blas Parera por el Primer Triunvirato, y adoptada y difundida por la Asamblea General Constituyente del año 1813.

Simultáneamente a la creación simbólica llevada a cabo por los actores políticos más influyentes de la época, surgía un sujeto social con lenguaje propio, el gaucho, a quien algunos miembros de la elite letrada le otorgaron voz a través de los cielitos patrióticos; este es el comienzo del género gauchesco. De este modo, el gaucho es politizado y puesto en la escena político-militar, haciendo uso de su voz y de su imagen con diferentes fines. El fenómeno que venimos relatando ha sido profundamente estudiado en el campo de la literatura; el propósito de este trabajo es indagar en este mismo sentido en relación con el ámbito de la imagen pictórica.

Creo que en este caso es la observación un factor crucial de la construcción de sentido en la formación de la identidad nacional argentina, como resulta ser la visión que se ha construido en torno al gaucho. Josefina Ludmer (2000) sostiene que la sustancia del género gauchesco es la relación entre voces oídas y palabras escritas. Afirma que: "el escritor del género usó las posiciones y tonos de la voz del gaucho para escribirlo, y en ese 
mismo momento le dio la voz al gaucho". En este sentido, debemos observar que la gauchesca no es la voz escrita directamente por el gaucho, sino la que le han asignado los letrados en los textos que conforman el género. La propuesta de Ludmer es medir los extremos finales de este género literario, su orilla inferior y superior, para ver cómo se define en la voz escrita del gaucho el hombre argentino. Otra observación relevante a los efectos de la problematización es que el desafío y el lamento, entendidos como los tonos de la patria, militarizados, politizados y ligados con una razón universal o un sistema de intereses, se dirigen siempre en el género contra el enemigo del que escribe. De modo tal, que la utilización de la voz del gaucho remite, en última instancia, a proveer una imagen del mismo, que sirva como arma en la confrontación de intereses por la asignación de sentido en la construcción de la nación.

La referencia a la gauchesca en cuanto género literario, sirve en este caso porque provee un marco de comprensión para investigar la utilización que se ha realizado en torno al gaucho por los contrincantes de la lucha en la definición de una identidad nacional, visto desde la pintura. Así, propongo revisar esta problemática desde el análisis de la imagen pictórica. Eduardo Grüner (2001) sostiene que "la imagen, y en particular la imagen pictórica (...) ha sido, históricamente, un aparato visual de constitución de la subjetividad colectiva y el imaginario histórico social". Y agrega además que "su función de transmisión ideológica, con ser indudable, es subsidiaria de su papel constructor de una memoria que busca fijar, por la mirada, el orden de pertenencia y reconocimiento prescripto para los sujetos de una cultura" [cursivas en el original]. Podemos decir entonces que la pintura nos ofrece un campo fecundo a la hora de analizar críticamente las miradas que se han hecho sobre los fenómenos político-sociales. En este sentido, coincido con Grüner en la idea de que hay políticas de la mirada de las cuales la pretensión de transparencia e incontaminación es sólo una de ellas; sin embargo, están también aquellas que pueden dar cuenta del barro y la sangre existente detrás de las imágenes. Mirar este fenómeno críticamente, incluye la reivindicación del secreto de las imágenes, ante la imposición ideológica de una presunta transparencia.

La relevancia de hacer un estudio de este tipo, radica no sólo en que no abundan los trabajos en este campo, sino sobre todo en que el pueblo argentino está próximo a cumplir el bicentenario de su revolución. En las vísperas de los festejos de 1910 cuando se debatía qué modelo de nación se deseaba, figuras clave como Leopoldo Lugones y Jorge Luis Borges (posteriormente, pero en el marco de los debates iniciados entonces) pusieron al gaucho y al género gauchesco en el centro de la escena, dando así respuestas a las problemáticas de su época. Ahora, cercanos a celebrar los doscientos años del origen mítico de nuestra nación, resulta pertinente buscar y debatir las imágenes del sujeto social que ha sido fijado por ciertas políticas de la memoria, como el inicio del ser nacional argentino.

\section{Palabras e imágenes en el período revolucionario (1810-1829)}

El período histórico que otorga marco temporal a este trabajo tiene una serie de peculiaridades que lo hacen bastante complejo a la hora de fijar la mirada en los sujetos sociales populares, máxime tratándose del gaucho, tema sumamente complejo del imaginario social y cultural argentino. Aquellos que intentan dar cuenta del verdadero sujeto rural de la historia argentina, se mofan de la folclorización del mismo a través de las diferentes manifestaciones artísticas, principalmente la pintura y la literatura. Contrariamente, hay quienes reivindican estos últimos aportes 
como verdaderos documentos de aquello que fue visto y oído por otros actores ${ }^{2}$. Siendo difícil acordar a rajatabla con alguno de esos extremos, considero que es posible pensar en una alternativa intermedia en que los documentos, relatos, poesías, dibujos, pinturas y demás insumos nos provean información para pensar al menos en un esbozo de lo que fue la vida popular rioplatense, no con el ánimo de reconstruir de modo arqueológico las ruinas de nuestra historia, sino para ver de qué modo ese pasado vivo sirve de testimonio a nuestro presente. La lectura a contrapelo propuesta por Walter Benjamin es una buena alternativa para hacer aflorar aquello que viene siendo ocultado o tergiversado por décadas.

Desde el punto de vista de la imagen, estamos en un período de precursores donde se destaca el marino inglés Emeric Essex Vidal. Era un momento convulsionado del naciente país donde las guerras de independencia ocupaban casi la totalidad del espacio público. No había todavía artistas locales ni extranjeros que se hubieran detenido a mirar Buenos Aires en detalle y menos aún sus sujetos sociales y costumbres. Otros artistas viajeros extranjeros sólo han producido vistas generales de la ciudad desde el rio (su vista al aproximarse a tierra) destacando el aspecto barroso de las costas, algunos pocos edificios al frente y la inmensa planicie pampeana dominando una escena desértica; a espaldas del muelle y sus cercanías, el horizonte infinito...

Emeric Essex Vidal era un marino inglés que llegó a las costas rioplatenses el 7 de mayo de 1816. Se encontraba en el buque de SMB 'Hyacinth' con estación en Brasil, ejerciendo el cargo de contador de su expedición. Parte

2 En todo caso la principal discusión es si sirven o no como documentos que hablen de la VERDAD de los hechos del pasado. Mi propuesta aquí es una discusión anterior que tiene que ver con la puesta en duda de la posibilidad de hablar de VERDAD en los hechos históricos. de ese tiempo (permaneció en Buenos Aires hasta septiembre de 1818) se desempeñó también como secretario del almirante de la escuadra. Luego, retornó a su país para continuar con otras expediciones. Vidal había decidido descender del buque y caminar por las calles de la naciente ciudad, así como aproximarse más allá de sus fronteras; de allí provienen sus acuarelas de gauchos o su entrono que es lo que en este trabajo nos interesa. Pero antes de eso, profundicemos un poco más en los motivos del viaje.

Durante las revoluciones y las luchas de independencia en América, y más aún posteriormente, el interés de los países europeos más avanzados en materia de desarrollo industrial por conocer los nuevos territorios libres cobra un impulso inusitado. Inglaterra es pionera en este sentido y sabemos la influencia que logra en Argentina en la formación de su política económica, en un momento en que buscaba diferenciarse de su otrora opresor peninsular. Se trataba entonces, a través de esos viajes, de conocer cuáles eran las riquezas y las posibilidades de explotación e inversión de capitales que pudieran realizarse. Más aún, según el testimonio del propio Vidal (1999) estamos en un momento en que el Imperio del Brasil busca extender su territorio hacia el Rio de la Plata, motivo por el cual forma un ejército de diez mil hombres para entrar en la Banda Oriental; para el año 1817 llega a ocupar Montevideo. Sin embargo, esto no durará mucho ya que ese ejército sería hostilizado por un amigo leal de la independencia (las palabras son de Vidal) como es José Gervasio Artigas. Según este relato, vemos también que la presencia del "Hyacinth" en nuestras tierras es una de las formas que utilizaban los británicos de poner límites al avance de los portugueses sobre el Río de la Plata, territorio que ellos mismos buscarán controlar por medios económicos después de unas invasiones frustradas. 
Realizado este breve recorrido contextual, quisiera considerar ahora algunas afirmaciones de dos estudiosos de Emeric Essex Vidal y eruditos en materia de arte. Alejo González Garaño (1943), su notable biógrafo ha dicho lo siguiente acerca del acuarelista: “espíritu curioso, observador e ilustrado, es indudable que se interesó vivamente por nuestro país y nos conoció bien; lo prueba la veracidad de su relato, los apuntes que tomó sobre las modalidades de nuestra vida y las numerosas acuarelas que pintó para representar lo que a su juicio se le ofrecía como característico". Por su parte, Bonifacio del Carril (1978) afirma en su texto, bajo el subtítulo Advertencia lo siguiente: "este libro ha sido concebido y realizado con el propósito de describir, sin ánimo de polémica, pero dentro de la más estricta verdad histórica, la figura del gaucho argentino, tal como fue en la realidad de los hechos, su tipo humano y social (...) a través de los artistas que fueron sus contemporáneos". Teniendo en cuenta lo que acabamos de transcribir, uno de los artistas que tomará como fundamental para trabajar la iconografía del gaucho es Vidal. A riesgo de simplificar sus afirmaciones, creo ver en los trabajos de estos estudiosos una perspectiva representacionista que considera que el artista ha volcado en la obra lo que sus ojos vieron como si fuera un reflejo exacto de la realidad. No quiero afirmar que la obra de Vidal carezca por ello de valor documental, que sin duda lo tiene, sino que me gustaría matizar un poco el tono categórico de las afirmaciones.

A propósito de esta problemática, Edward Said puede brindarnos algunas ideas y categorías analíticas pertinentes para complejizar el tema. En su texto titulado "Orientalismo" (2004) ha definido dicho término como "... un modo de relacionarse con Oriente basado en el lugar especial que éste ocupa en la experiencia de Europa occidental". De esta manera Oriente aparece casi como una invención europea que permite a Occidente forjar una identidad en base a una representación que se hace sobre lo/los otro/s. De modo tal que Oriente aparece como una parte integrante de la civilización y la cultura material europea; en este sentido, la representación de oriente estaría hablando más bien de Occidente que del propio Oriente ${ }^{3}$.

Está claro que el Río de la Plata no pertenece a Oriente, aunque esta idea puede resultar útil para pensar el modo en que los viajeros extranjeros miraban a sus otros ${ }^{4}$. Serán en muchos casos los seres exóticos que veían los conquistadores y los viajeros posteriores, tal como dijera Tzvetan Todorov (1991), a partir de sus extraordinarias indagaciones de los discursos. Retomando a Said, me parece importante considerar uno de los recaudos que el autor dice haber tenido para sortear los problemas de la distorsión y la inexactitud. Se trata de la distinción entre conocimiento puro y conocimiento político; Said argumenta que el consenso general que sostiene que el conocimiento verdadero es fundamentalmente no político (y al contrario el conocimiento político no es verdadero) sólo oculta las condicio-

3 En este sentido Said dice que "si tomamos como punto de partida aproximado [del orientalismo] el final del siglo XVIII, el orientalismo se puede describir y analizar como una institución colectiva que se relaciona con Oriente, relación que consiste en hacer declaraciones sobre él, adoptar posturas con respecto a él, describirlo, enseñarlo, colonizarlo y decidir sobre él; en resumen, el orientalismo es un estilo occidental que pretende dominar, reestructurar y tener autoridad sobre Oriente" (2004).

4 En el caso de la Argentina, la expresión más exacerbada de una mirada orientalista hacia nuestro propio país es la de Domingo Faustino Sarmiento. Tras haber realizado un extenso viaje por Europa y Asia donde experimentó y conoció muchas de las ideas evolucionistas en boga y leía a Gobineau con fruición, dará su veredicto acerca de los sujetos populares argentinos; así, recomendará no ahorrar sangre de gaucho, esos beduinos de América. 
nes políticas oscuras que rigen la producción de cualquier conocimiento. Agrego por mi parte que la concepción representacionista en materia de arte es una manifestación de este tipo. No estoy de acuerdo con la idea de que una imagen represente la verdad de los hechos, por estar supuestamente desprovista de intenciones políticas ${ }^{5}$.

Siguiendo esa lógica, debo decir que tal como vimos anteriormente, Vidal pertenecía a un grupo de navegantes que se embarcaron hacia América con fines precisos. Aunque no haya tergiversado las imágenes que pintó, es claro que se ha detenido a capturar imágenes de aquello que a sus ojos era importante que fuera visto; además, para no dejar lugar a dudas, completó sus imágenes con textos explicativos. Alertar sobre estos asuntos, ¿significa que sus acuarelas no sirven para ayudarnos a comprender la historia? Claramente no es eso lo que pretendo afirmar, simplemente deseo observar que las imágenes pictóricas pueden aportarnos mucho a nuestra comprensión del pasado pero tomando los recaudos necesarios. Veamos un ejemplo al respecto. Vidal creía que realizar acuarelas de la vida cotidiana de ciertos sujetos sociales, sus oficios, actividades, los edificios de la ciudad y otras cosas, sería importante para que quienes las vieran pudieran comprender la sociedad de ese momento en el Río de la Plata (de hecho saldrá editado en Inglaterra a su regreso en una edición de excelente calidad para la época y de altísimo valor). En una acuarela suya sobre los mataderos, se ve la impresión que le habían causado al visitante los trabajos que allí se realizaban; en el texto explicativo agregaba que nada era más repugnante que ver cómo se llevaban allí

5 Respecto a esta temática, atiendo fundamentalmente los argumentos que Walter Benjamin sostiene en sus obras, principalmente La obra de arte en la época de su reproductibilidad técnica e Historia y coleccionismo: Eduard Fuchs. las reses y cómo eran matadas al aire libre, hubiera o no polvo o lodo. Sin embargo, puede verse a lo largo de su obra una serie de detalles que sirven para comprender rasgos sociales y culturales de la época. Por ejemplo, el sujeto anterior al gaucho del Río de la Plata (el camilucho o gauderio) utilizaba el calzoncillo cribado y el calzón español que había heredado de los conquistadores. En la época que Emeric Essex Vidal viene a nuestras costas los gauchos más pobres ya habían adoptado como prenda de vestir el chiripá ${ }^{6}$ que utilizaban los indios pampas. Esta costumbre del gaucho se irá extendiendo con el tiempo hasta llegar al momento en que todos ellos, indistintamente de su condición socioeconómica, dejen de utilizar el calzón y adopten el chiripá. Vidal documentó en sus acuarelas esta época de transición. Así, es posible distinguir en sus varias acuarelas la condición social del gaucho a partir de la vestimenta que utilice.

En otro texto, dirá Said (1996) refiriéndose al lenguaje o más precisamente a las palabras, que éstas han dejado de ser un medio transparente a través del cual el ser brillaba. Desde Wasserman, Auerbach y otros se ha dejado de ver al lenguaje como el intento de representar la realidad miméticamente. De este modo, tal como dijéramos en el párrafo anterior, es preciso ver al lenguaje y las obras pictóricas así como otros testimonios, situados en un contexto sumamente complejo que dista mucho de ser aséptico; más aún, están condicionados por la compleja urdimbre social, cultural, política y económica de la sociedad. Al referirse al término colonizado, Said afirma que esa condición “.... se convirtió en un destino duradero, incluso de resultados totalmente injustos, sobre todo, después de que se había logrado la independencia nacional" (Said, 1996). En nuestro caso de estudio, esto

6 Era una especial de poncho rectangular que se utilizaba doblado y hacía las veces de pollera. Esta prenda reemplazaba el calzón español. 
se da no solamente porque, como afirmara Tulio Halperín Donghi (2008), transitamos un pasaje del orden colonial al neocolonial, sino también porque el estatus de estos pueblos ha quedado fijado de diversos modos en zonas de dependencia y periferia. En este sentido, no podemos dejar de advertir que los valiosos testimonios de Vidal provienen de una misión inglesa que pretenden convertir a Argentina en una zona de influencia para su comercio; para esto, era importante entre otras cosas conocer los ‘tipos sociales' y 'usos y costumbres' de quienes la poblaban.

En otro orden de cosas, la literatura gauchesca puede darnos también algunas herramientas para profundizar la indagación que venimos desarrollando. Si queremos tener una visión más profunda acerca del sujeto social que nos ocupa, es necesario atender los aportes de la poesía gauchesca. Hemos dicho con anterioridad que Bartolomé Hidalgo es el fundador del género; es también el único poeta gauchesco que podemos consultar para el período que nos propusimos indagar aquí, tal como ocurre con Vidal para el caso de la pintura. Según Josefina Ludmer (2000), con Hidalgo se produce una revolución literaria ya que la propia literatura ha tenido que bajar su orilla inferior para incorporar lo nunca antes escrito, y las "voces bajas" de los sectores subalternos necesitaron un ascenso para hacer oír una voz nunca antes oída desde una institución disciplinadora como lo es la propia literatura. Así, incorporando lo nunca antes escrito, se ampliaron los límites de lo literario. El rasgo esencial de los diálogos y cielitos de Hidalgo no es el hecho de que habla acerca de los gauchos, sino que escribe directamente las voces oídas de los mismos. Mejor aún, escribe los versos como si fueran la propia oralidad de los gauchos inscripta en una lógica institucional: la literatura. Para ello, se ha necesitado de versos escritos de modo particular que respete dicha oralidad. Así, aparece con Hidalgo el rasgo central de la gauchesca que es la fusión de las voces oídas con la palabra letrada. "A partir de la voz oída del gaucho, la alianza articula el mundo de los sujetos, su espacio interno, con la patria..." (Ludmer, 2000). Los sentimientos que el gaucho expresa a través de la pluma del letrado, son también formas de participación en la lucha por la construcción del espacio de la patria. No podemos dejar de indagar entonces en el contexto del letrado que da voz a nuestro sujeto social; pero, una vez más, podemos hurgar allí también para buscar testimonios que nos ayuden a comprender el lugar que ese mismo sujeto ha tenido en nuestro pasado.

Bartolomé Hidalgo nació en Montevideo en 1788 en el seno de una familia de condición social modesta. En 1803, al contar con quince años, entra de dependiente en el comercio de Martín José Artigas, padre del caudillo oriental. Tuvo por esto una intensa vida política y militar en un tiempo en que era difícil hacerse ajeno a estos temas. Así, en 1806 trabaja en el Ministerio de Real Hacienda, combate las invasiones inglesas en la acción del Cardal y, más importante para nuestro propósito, en 1811 acompaña a las tropas artiguistas en Paysandú y Salto. Junto con estas actividades, cultivó con intensidad el periodismo y la escritura, compuso la letra a la Marcha Nacional Oriental. Recién en sus últimos tres años de vida dedicará más tiempo a la poesía, produciendo la mayor cantidad de diálogos y cielitos. Sabemos entonces que Hidalgo ha servido en la casa del padre de la patria, así como en las filas de su ejército. Esta situación le dará una experiencia característica que se reflejará en su modo de dar voz al gaucho en la poesía, sujeto con el que había compartido años de luchas y batallas en un frente común.

Según Bonifacio del Carril (1978) encontramos los primeros registros de la palabra "gaucho" (aunque no el sujeto social que es producto de un devenir a lo largo del tiempo) luego de las revoluciones, 1810. En un 
primer momento se utilizará para designar de modo despectivo a los sujetos populares del ámbito rural. Pero serán los ejércitos heroicos de Güemes en Salta y de Artigas en la Banda Oriental los que otorguen nuevo significado al concepto, después de las luchas por la independencia. Las tropas estaban conformadas principalmente por gauchos que habían defendido con éxito las fronteras de los embates del ejército realista. Sin embargo, en los diversos documentos en que la palabra aparece escrita, es cambiada o matizada por las crónicas porteñas del momento, ya que se trataba de una palabra incómoda; después de todo, ¿cómo era posible que la frontera del país estuviera confiada a esos sujetos?

Hidalgo ha puesto como protagonistas de sus cielitos y diálogos a gauchos que realizan sus relaciones acerca de temáticas básicas de la formación de una identidad nacional, asuntos en los que su voz no era contemplada ya que se resolvían en el espacio privado de las oligarquías que se apropiaban del espacio público. Muchos son los temas que se tratan en sus obras siendo uno de los más recurrentes los festejos o análisis de las victorias obtenidas frente a los españoles. Me gustaría detenerme brevemente en algunos versos de un diálogo en que los dos gauchos protagonistas discuten sus ideas sobre la justicia y la igualdad. Para comprender más claramente este tema, quisiera traer a la discusión algunos aportes del pensador francés Jacques Derrida.

Desde el comienzo de su artículo Fuerza de ley, Jacques Derrida nos advierte acerca del equívoco de equiparar justicia y derecho. Discutiendo el título de un coloquio ( $L a$ deconstrucción y la posibilidad de la justicia) se pregunta si la deconstrucción asegura o permite la posibilidad de la justicia. Aquí, se responde, habrían dos partidos: aquellos que digan que sí y aquellos que afirmen que la deconstrucción constituye una amenaza contra el derecho y por tanto arruina la condición de posibilidad de la justicia. En esta última afirmación está el error, que consiste en pensar que justicia y derecho son iguales. El primero en distinguir las leyes de la justicia fue Montaigne; según él “...las leyes (...) mantienen su crédito no porque sean justas sino porque son leyes. Es el fundamento místico de su autoridad, no tienen otro (...) El que las obedece porque son justas, no las obedece justamente por lo que debe obedecerlas" (Derrida, 1992). Aquí se evidencia que las leyes no son justas en tanto que leyes; no se obedecen por ser justas sino porque tienen autoridad.

Distinguidas justicia y derecho, resta ver si es posible realizar la deconstrucción. El derecho es esencialmente deconstruible porque está fundado, construido sobre capas textuales interpretables y transformables, y porque su último fundamento, por definición, no está fundado. De este modo, la justicia en sí misma no es deconstruible, así como tampoco lo es la misma idea de la deconstrucción. Resumiendo, la deconstruibilidad del derecho hace la deconstrucción posible, y la indeconstruibilidad de la justicia hace también posible la deconstrucción, es decir, se confunde con ella. La consecuencia de todo esto es que la deconstrucción encuentra su sitio en el intervalo que separa la indeconstruibilidad de la justicia y la deconstruibilidad del derecho.

Por este mismo carácter de la justicia, debemos aclarar que para el pensador francés no podemos tener experiencia de la justicia debido a que se trata de un camino aporético. La justicia se erige en la experiencia de aquello de lo que no se puede tener experiencia. Pero por otra parte no hay justicia sin la experiencia, por muy imposible que sea, de la aporía. La justicia es así una experiencia de lo imposible, está inscripta en un quizás: funciona dentro de la lógica de la posibilidad.

"De esta paradoja se sigue que en ningún momento se puede decir presentemente que una decisión es justa (es decir, libre y res- 
ponsable) o que alguien es justo..." (Derrida, 1992). En vez de eso, se puede decir legal o conforme al derecho. Siempre hay que considerar que en el acto de institución de este derecho, se habrá planteado el mismo problema de la justicia, violentamente resuelto, enterrado y rechazado. Para Derrida el mejor ejemplo y paradigma de lo que acabamos de decir, está constituido por la formación de los estados-nación o el acto instituyente de una constitución que instaura el estado de derecho.

En el "Diálogo patriótico interesante" de Bartolomé Hidalgo (1979) aparece un intercambio de ideas entre los personajes Chano y Contreras que me parece pertinente reproducir ya que está directamente relacionado con lo que venimos afirmando. Dice Contreras:

Pues yo siempre oí decir/ que ante la ley era yo/igual a todos los hombres. Chano, el capataz que mantiene con Contreras una relación didáctica le responde: pero hay sus dificultades/ en cuanto a la ejecución./ Roba un gaucho unas espuelas,/ o quitó algún mancarrón,/ o del peso de unos medios/ a algún paisano alivió;/ lo prienden, me lo enchalecan,/ y en cuanto se descuidó/ le limpiaron la caracha,/ y de malo y saltiador/ me lo tratan, y a un presidio/ lo mandan con calzador;/ aquí la lay cumplió, es cierto,/ y de esto me alegro yo;/ quien tal hizo que tal pague./ Vamos pues a un Señorón;/ tiene una casualidá.../ ya se ve... se remedió.../ Un descuido que a un cualquiera/ le sucede, sí señor,/ al principio mucha bulla,/ embargo, causa, prisión,/ van $\mathrm{y}$ vienen, van y vienen,/ secretos, almiración,/ ¿qué declara? que es mentira,/ que él es un hombre de honor,/ ¿Y la mosca? No se sabe,/ el Estao la perdió,/ el preso sale a la calle/ y se acaba la función./ ¿Y esto se llama igualdá?/ ¡La perra que me parió!..

En este diálogo vemos claramente una crítica al modo en que el derecho actúa sobre los sujetos sociales populares. Si bien Chano acepta que se debe pagar por los males que se provoca, maldice el momento en que el derecho se aplica castigando al desposeído (el gaucho), pero deja libre al señorón que posee dinero y puede arreglarlo. Aquí se critica unas leyes que se aplican a discreción y se pone en tela de juicio tanto la justicia como la igualdad. Creo que estamos frente a un cuestionamiento de la legalidad, que no se presenta como portadora de justicia, sino como arbitrariamente aplicada según la condición social de quien deba ser disciplinado. Hidalgo presta su pluma a sujetos cuyo espacio de enunciación tal vez nunca hubiera tenido lugar si no hubiese comenzado ese proceso de revolución literaria de que habla Ludmer. De todas formas, como lo hicimos con Vidal, tenemos que advertir que no es el gaucho mismo quien ha escrito esos versos; tampoco se trata de una transcripción de un diálogo oído y reproducido. Nuevamente, se trata de tener en cuenta esos factores, pero ver además qué pueden aportarnos a nuestra comprensión del gaucho.

La pregunta que propongo discutir ahora gira en torno a la problemática que plantea Dipesh Chakrabarty (1999) acerca de las "historias de las minorías" y el rol de la historia como disciplina académica a la hora de incorporar en el relato estos pasados subalternos. Tratar este tópico en torno a mi propuesta es importante ya que la misma se basa, en última instancia, en alejarme de las perspectivas excluyentes acerca de la narrativa nacional. En el caso que me he propuesto trabajar la complejidad está dada no sólo por la exclusión de la voz de ese otro, sino sobre todo por la tergiversación y utilización de esa voz con otros fines. La 
dificultad de encontrar un propio espacio de enunciación del gaucho se suma a la creación de un espacio tal por actores letrados, con el fin de dirimir en el ámbito de lo simbólico y cultural la lucha por la construcción de un imaginario colectivo en torno a la idea de nación.

Quisiera ahora establecer una precisión terminológica para delimitar mejor el debate. Para ello tomaré prestada la idea de pasados subordinados o subalternos que propone Chakrabarty. El autor afirma que la idea de minoría debe ser entendida en principio como una construcción. Así, hay dos modos diferentes de comprenderla; por una parte, en sentido estadístico significa un grupo minoritario desde el punto de vista numérico. Pero por otra $-\mathrm{y}$ esto es lo central de su argumentación- puede entenderse “...como instancias de "inmadurez", pasados que no nos preparan ni para la democracia ni para las prácticas ciudadanas al no estar basados en el despliegue de la razón en la vida pública" (Chakrabarty, 1999). En este sentido, los pasados subalternos resisten la historización en tanto son considerados como infantiles desde el punto de vista de la racionalidad; así, no poseen un relato que pueda aportar a la comprensión del desarrollo histórico moderno ${ }^{7}$. La dificultad que viene a señalar Chakrabarty (que él mismo y el grupo de estudios subalternos deben enfrentar) es que

$7 \quad$ Hegel ha sido uno de los teóricos que más profundamente se ha ocupado de brindar un fundamento filosófico al modo de comprender el desarrollo histórico de la humanidad. Según su concepción teleológica de la historia, el punto culminante de la historicidad se produce en los pueblos germanos siendo el resto de las culturas estadios primitivos de desarrollo. América sería en su visión un pueblo sin historia en la medida en que ni siquiera ocupa los estadios más primitivos. Para un trabajo extraordinario acerca de las diversas concepciones de la historia y su repercusión en América, es indispensable el trabajo de Alcira Argumedo "Los silencios y las voces de América Latina". los pasados subalternos nunca pueden entrar en la historia como parte de la posición propia del historiador. En su afán de explicación racional del pasado tal como la disciplina científica lo exige, el historiador no puede invocar o recurrir a lo sobrenatural para explicar los hechos tal como podría eventualmente hacerlo la propia "minoría" acallada. Este hecho nos advierte sobre todo que la historia es solamente uno de los modos posibles de recordar el pasado y no el único; la disciplina encuentra allí sus propios límites.

Este mismo autor dirá en consecuencia que los pasados subalternos pueden ser pensados como nudos cerrados que quiebran la matriz llana del tejido. Entre la explicación del historiador y la propia visión del sujeto subalterno acerca de su experiencia, hay un hiato o vacio que separa dos experiencias diametralmente distintas de historicidad. La tesis central de Chakrabarty es que ese vacio no puede ser llenado por un ejercicio que convierta sus afirmaciones en 'evidencias' por más que creamos entenderlas claramente. La salida que propone el autor es asumir que "no existe una tercera voz que asimile en sí misma las dos voces distintas $(. .$.$) , tenemos que que-$ darnos con ambas, y con el vacío que existe entre ellas, lo cual señala una pluralidad irreductible en nuestras propias experiencias de la modernidad" (Chakrabarty, 1999). Aparece de esta manera la cuestión del dislocamiento del tiempo, en tanto los archivos nos ayudan a visibilizar la naturaleza dislocada de nuestra propia época. Según Chakrabarty esa es la función de los pasados subalternos. Es claro el tinte derridiano de esta idea, en tanto la disyunción en el tiempo nos habla de una justicia que debe ser presente, pero que es preciso pensar en diálogo con las injusticias de nuestro pasado. Los límites de la historia que salen a la luz cuando buscamos considerar esos pasados subalternos, nos señalan que hay algo más que no puede ser rechazado ni rellenado con recursos meramente racionales. 
Ese hiato que nos incomoda por la dificultad que trae consigo a la hora de hacerlo inteligible en términos racionales, es indispensable si queremos comprender el pasado incorporando voces y experiencias que exceden los propios límites de la historia como disciplina.

En el mismo sentido propuesto por el autor para pensar los pasados subalternos de las minorías, intento comprender al gaucho como sujeto social para el caso de Argentina. Es cierto que Chakrabarty estudia otros espacios donde sus categorías pueden ser aplicadas de modo más pertinente por haber sido pensadas para esos casos; sin embargo, creo que sus observaciones pueden arrojar luz a otras realidades teniendo en cuenta las diferencias. En el mismo sentido que habla el autor, el gaucho puede ser visto como grupo minoritario no necesariamente por la variable numérica, sino por haber sido concebido en muchos casos como un factor irracional y de atraso para ciertos sectores que pugnaban por imponer su proyecto nacional. Por este mismo motivo, este actor ha sido excluido como sujeto activo en el relato nacional, aunque se haya incorporado posteriormente para paliar lo que se consideraba como otro problema de la coyuntura histórica. Sin embargo, creo que es posible hallar testimonios que permitan siquiera atisbar una comprensión de esas voces acalladas, reconociendo que ante la imposibilidad (y tal vez la indeseabilidad) de adoptar totalmente sus posturas, visiones y voces de modo transparente, debemos dejar lugar al hiato que separa su experiencia del tiempo, de la nuestra.

Gayatri Spivak (1985) presenta otra visión acerca de esta problemática que radicaliza el tema de la posibilidad del subalterno de tener un espacio de enunciación. La autora está absolutamente en contra de la idea de representación del otro. Por mi parte, creo que esta postura de no representación del/os otro/s es estimable en el sentido que nadie puede arrogar para sí mismo la certeza de ser un portador transparente de su identidad; sin embargo, creo también que la postura de Spivak corre el riesgo de llevarnos a un inmovilismo por el modo en que concibe el acto de representación. Sostiene que "para el 'verdadero' grupo subalterno, cuya identidad es la diferencia, no hay, en rigor, sujeto subalterno irrepresentable que pueda conocer y hablar por sí mismo. Pero la solución de los intelectuales se halla en no abstenerse a la representación" (Spivak, 1985). Por mi parte, creo que hurgar en las ruinas del pasado los vestigios de las voces de los acallados no es un mero intento de representarlos y continuar con una suerte de violencia epistémica sistemáticamente aplicada. La postura radical de Spivak está sostenida en la idea de que el sujeto subalterno no tuvo un lugar de enunciación, siendo esa misma situación la que lo convierte en tal. Si fuera posible asignarle un espacio de enunciación, si hubiesen tenido voz, no se trataría entonces de sujetos subalternos. ¿Qué podemos hacer entonces para incorporar estas voces (in)existentes al relato nacional? La respuesta de Spivak parece ser que no hay nada que pueda hacerse ya que por su condición de subalternos no hay voces disponibles. Su propuesta parece reducirse únicamente a intentar buscar espacios de enunciación para los acallados de hoy para que, pudiendo hablar, estos sujetos salgan de su condición de subalternos.

En lo que a mí respecta, tiendo a estar más de acuerdo con la propuesta de Chakrabarty y no por mero optimismo. Creo con Derrida que no es posible ser justos e intentar vivir la experiencia de la justicia por más aporética que sea, si no contemplamos que nuestra historia tiene voces silenciadas que fueron excluidas del relato nacional y que sin embargo nos reclaman justicia. Es cierto que no podemos ponernos en el papel de portavoces legítimos de los sujetos subalternos bajo la actitud paternalista de la representación, pero 
también es cierto que si somos cautos y tenemos en cuenta que hay un hiato o vacío entre sus propias experiencias y las que nosotros podemos leer, puede ser éste un testimonio valioso para interpelar un presente que no ha saldado aún sus deudas ni con el pasado, ni consigo mismo.

\section{Conclusión}

Tal como hemos visto al principio de este trabajo, se han realizado intentos académicos de situar al gaucho en tanto sujeto social, en una dimensión histórica que le provea renovadas posibilidades de acción. Pero además, estas búsquedas de un redimensionamiento en el plano sociopolítico para el gaucho, han operado bajo el supuesto de que era necesario buscar los archivos históricos, las leyes, etc. y dejar de lado los elementos subjetivistas. Dentro de estos últimos, encontramos por ejemplo a la literatura y la pintura. Según ese enfoque se trata de una folclorización que oculta al sujeto social que habitó el suelo rioplatense. Considero que se trata de investigaciones sumamente útiles para comprender y situar socio-históricamente al gaucho, pero adolecen de materiales que pueden resultarnos de gran ayuda para ver otras aristas de la problemática que nos ha convocado. Con ese espíritu, he intentado acercarme a algunas pinturas y diálogos para ver si efectivamente podían decirnos algo, o simplemente eran vanas tergiversaciones del sujeto que nos dificultaban más nuestra tarea.

Desde el comienzo he dejado claro que la perspectiva directriz que iluminaba esta indagación, era la de Walter Benjamin. En este sentido, he procurado recabar algunos elementos que permitieran dar luz al fenómeno sin buscar una reconstrucción del pasado tal cual fue, sino, convencido de que la historia es un relato entre tantos otros, ver qué es lo que puede decirnos hoy ese pasado. Ver, en todo caso, de qué modo nos interpelan los sujetos subalternos del pasado y confrontarlo con las imágenes de ellos mismos que nos han legado otros actores sociales. Así como la noticia no es más que el relato de un acontecimiento, la historia es una narrativa que relata los sucesos del pasado. Como tal, no es ni debería pretender ser transparente; digamos nuevamente, con Grüner, que la pretensión de transparencia incontaminada es una posición política. Esta suerte de contaminación, sucede con todos los documentos que podemos revisar para interpretar el pasado. De este modo, no veo el motivo por el cual deberíamos tomar algunos y descartar otros; si tomamos en cuenta la complejidad que tiene la utilización de documentación visual, podemos legítimamente utilizarla para enriquecer nuestro estudio.

El grupo de estudios subalternos ha aportado muchas herramientas para pensar la profundidad que tiene la búsqueda de la voz de los subalternos en la historia. La discusión historiográfica brindada por Chakrabarty es un buen ejemplo de reflexión en torno a esa problemática. Creo que su crítica es sumamente estimulante para continuar el trabajo en ese sentido, a pesar de una dificultad que a veces se nos presenta como insalvable. Estoy de acuerdo con la idea de un vacío entre nuestra interpretación del pasado de los sectores subalternos y su propia experiencia al respecto; o, más bien, su propio modo de recordarlo que muchas veces entra en contradicción con las explicaciones que pueden dar las disciplinas científicas. Si tomamos en cuenta que hay un hiato y lo hacemos parte de nuestra interpretación estando ahi, aunque no podamos desarrollarlo, aunque nos incomode en nuestro intento por explicarlo todo, entonces habremos enriquecido nuestro estudio. La solución de Spivak en este asunto no parece dar perspectivas de justicia; dije estar de acuerdo con su idea de no representar al otro como si hubiéramos sido capaces de comprenderlo para erigirnos 
en sus portavoces. Sin embargo, no estoy de acuerdo con lo que parece ser un inmovilismo: dejar de buscar voces que no están porque, si existieran, no serían subalternas. En cambio, su propuesta parece ser la de dar espacios de enunciación a sectores acallados de hoy; así -sigo su lógica- tendrían voz y no serían subalternos. ¿Podemos creer que por ese ejercicio de traducirlos y difundirlos estamos dándole voz? ¿No es acaso una actitud paternalista que pretende dar a conocer algo a un público determinado que no necesariamente constituirá un público? ¿Será eso efectiva comunicación? Son interrogantes estimulantes para discutir en torno a nuestra tarea como investigadores. Creo haber dejado en claro cuál es mi opinión al respecto: la des-estetización de las imágenes pictóricas y literarias pueden ayudarnos a comprender la problemática del gaucho con mayor profundidad. Tratándose de testimonios de letrados o artistas, no de los propios actores sociales, traen una complejidad intrínseca que es posible salvar si los ubicamos contextualmente. Si concebimos nuestra labor como un intento de búsqueda de justicia, tal como yo mismo quisiera hacer con mi trabajo, debemos dejar intacto ese hiato aunque nos perturbe. En este caso, Emeric Essex Vidal y Bartolomé Hidalgo han puesto sus vidas en juego en cada una de sus obras; sin embargo, a pesar de haberlas contaminado con sus propias experiencias, y quizás por ello mismo, sus testimonios son inestimables para comprender hoy las visiones del sujeto que nos ha convocado. Abandonar nuestra tarea crítica de interpretar el pasado por la existencia de esos vacíos incomprensibles, ¿no será acaso un intento desesperado por salvar la pureza incontaminada de la razón? Si nuestro modo de explicar los hechos sociales entra en contradicción con los propios hechos, ¿no deberíamos más bien criticarlo y complejizarlo con otras formas de comprender la realidad?

\section{Referencias}

Benjamin, W. (1979). Discursos Interrumpidos. Madrid: Taurus.

Buch, E. (1994). Ojuremos con gloria morir. Buenos Aires: Sudamericana.

Chakrabarty, D. (1999). Historias de las minorías, pasados subalternos. Revista Historia y grafía, 12, (6), 87-111.

Del Carril, B. (1978). El gaucho. A través de la iconografía, Buenos Aires: EMECÉ.

Derrida, J. (1992). Fuerza de ley: el fundamento místico de la autoridad. Madrid: Tecnos.

Derrida, J. (2003). Espectros de Marx. Madrid: Trotta.

González Garaño, A. (1943). Iconografía argentina. Anterior a 1820. Buenos Aires: EMECÉ.

Grüner, E. (2001). El sitio de la mirada. Buenos Aires: Grupo Editorial Norma.

Hidalgo, B. (1979). Cielitos y diálogos patrióticos. Buenos Aires: Centro Editor de América Latina.

Ludmer, J. (2000). El género gauchesco: un tratado sobre la patria. Buenos Aires: Perfil Libros.

Pratt, M.L. (1997). Ojos Imperiales. Literatura de viajes y transculturación. Buenos Aires: Universidad Nacional de Quilmes.

Said, E. (1996). Representar al colonizado. Los interlocutores de la antropología. En González Stephan, B. (ed.) Cultura y Tercer Mundo. Cambios en el saber académico, Tomo I, Caracas: Nueva Sociedad. 
Said, E. (2004). Orientalismo. Barcelona: Sudamericana.

Spivak, G. (1985). ¿Puede el subalterno hablar? Revista Orbis Tertius, 6, (3), 175-235.
Todorov, T. (1991). Nosotros y los otros. Reflexión sobre la diversidad humana. España: Siglo XXI.

Vidal, E.E. (1999). Buenos Aires y Montevideo. Buenos Aires: EMECÉ. 